\title{
English Teaching Strategies: Enhancing the Subject Matter Knowledge of Pre-Service Teachers
}

\author{
Janet E. McIntosh \\ Schulich School of Education, Nipissing University, Canada
}

\begin{abstract}
Pre-service English teachers with limited subject matter knowledge of literature face challenges when they are teaching some texts in secondary school classrooms. A Canadian teacher educator's concern about this issue and its impact on novices' competency in the teaching of English prompted further exploration. This research focuses on the teacher educator/researcher's experience with adapting her teaching strategies in an English methods course in order to better meet the needs of pre-service teachers, secondary students and the profession's expectations for the field of English teaching. Emphasis was placed on choosing strategies that could assist pre-service teachers with developing further subject matter knowledge. Teaching strategies implemented included selection of books for reading, book talks, Senior English novel reading, reader response journals, and book groups. Observations about the pre-service teachers' use of the strategies were made by the teacher educator in the form of reflective notes. Course participants engaged in using the five strategies, interweaving the strands of reading, writing, and speaking. Assignments were built around the strategies, and pre-service teachers revealed development of subject matter knowledge and increased confidence in text awareness. As observational evidence revealed positive results in implementing the five strategies, further use of these strategies will continue next year. Continual rethinking of one's practice as an English educator may enhance the possibilities for best practices to be developed in future teachers of English.
\end{abstract}

\section{Introduction}

Pre-service teachers who have limited subject matter knowledge of contemporary literature face challenges when they are teaching these texts in secondary school practicum classrooms. For the past three years, a Canadian teacher educator has been concerned about this issue and its impact on novices' competency in the teaching of English. As the study of literature has continued to be a central organizing discipline of college and secondary school English teaching [1], competence in this area is important for pre-service teachers. According to Langer [2], "literature is at the heart of what is to be learned" (p. 114). Subject knowledge is defined as "having both content and pedagogical (subject-specific) components; these two knowledges overlap as the first is needed to teach the subject" [3], (p. 111). Grossman and Schoenfeld [4] reinforce that "prospective teachers need a solid foundation in the subject matters they plan to teach" (p. 206). This aspect is supported by Shulman [5] whose extensive research lays out a knowledge base for teaching and pedagogical content knowledge; a teacher needs to know the content extensively, and "must possess knowledge of the subject to be taught" (p. 8).

\section{Literature Review}

For the past 13 years, a teacher educator and researcher's practice has been to focus on introducing and modeling various teaching strategies rather than teaching the content itself. Extensive practice in the use of instructional methods, rather than building on pre-service teachers' content knowledge is supported in Literacy Teacher Education research [6]. Within the parameters of a one year teacher education program in Canada, opportunities for detailed study or teaching of texts are reduced. The expectation is that students in this professional program would have already completed study of some literature in secondary school; for the specialists in English, their undergraduate degree programs would have focused on extensive study of various texts from different time periods. Feiman-Nemser [7] states that "for a long time, teacher educators took subject matter preparation for granted, relying on the fact that prospective teachers completed a specific number of courses...serious questions have been raised about the adequacy of teachers' subject 
knowledge" (p. 1020). It is important to consider that even when teachers specialize in their teaching subjects, there may be gaps in their acquired knowledge.

Professional texts such as Teaching Literature to Adolescents [8] serve as a resource for teaching methods. According to the National Council of Teachers of English guidelines for the preparation of teachers of ELA [9], an emphasis is placed on teacher candidates having "a broad knowledge of literature not just as literary spectators; they should know literature from the inside" (p. 30). Awareness of particular texts for classroom study is an ideal starting point. Recent research by Watkins and Ostenson [10] emphasizes that in English teaching methods courses, "we should increase teacher candidates' awareness about the wide range of available texts...introducing our students to resources to help identify the best titles would be valuable" (pp. 269-270). In addition, personal experience with reading, reflection, and study of texts enhances understanding; it may transfer into best teaching practices thereby benefitting English students in secondary classrooms.

In Canada, opportunities for studying national texts (novels, short stories) are offered through the provincial English curriculum in secondary schools [11]. Prompted by her desire to impact positive change, the teacher educator become involved with a Canadian publisher, and took on an Education Advisor role. She contributed to creating contemporary CanLit resources [12]; digital versions were also published [13]. Helping pre-service teachers keep current with secondary classroom texts is an appropriate step. If texts are unfamiliar, novice teachers may be uncomfortable implementing them in their classroom teaching.

\section{Research}

This research explores the view that without preservice teachers having a solid base of knowledge, it may be ineffective for an English teacher educator to be using her past approach in a methods course. It doesn't seem sufficient to be working from the premise that text content has already been learned, and then building on practical strategies for text study. How can a teacher educator enhance the subject matter knowledge of her pre-service teachers in an English methods course, thereby building on their competencies in guiding text study with their future secondary students?

In the process of adapting her approach to address current needs of pre-service teachers, she has given careful consideration to how this change in practice may be implemented.

\subsection{Teaching Strategies}

Teaching strategies chosen and developed for English methods course inclusion by the teacher educator were as follows: selection of books for reading, book talks, Senior English novel reading, reader response journals, and book groups. Each strategy became an integral part of the course assessment; required assignments were built around these strategies. The teacher educator's goal was to select specific strategies and implement them with course participants in order to help them develop and possibly deepen their subject matter knowledge.

In this section, each strategy will be described and a rationale provided for the process. During the second week of the course, the teacher educator introduced the selected book strategy. Pre-service teachers were given the opportunity to choose a book from a collection of 40 provided by the course professor. They would read that book, and present a book talk to peers. These books were recommended for study in grades 7-12 English classrooms. In Canada, students in these classes would be of ages 12-17. Most of the texts were fiction, although a few were non-fiction, and many were contemporary titles (published in last 10 years). Past experiences of the course professor had made her aware that engagement with books could be increased if students have the chance to study some newer texts in English classrooms at secondary school level.

Guided selection might be a better term for this aspect of the strategy, as open, independent choice of books beyond the collection was not the process employed. The reason for this decision was that when open choice was used a few years back, most pre-service teachers seemed to select a book they had already read when they were students in school. Re-visiting a book at a different time in one's life can be a rewarding experience, but the teacher educator's intent was clear. Although many of the previously read books were likely worthy of classroom study, her desire was to expose the course participants to books beyond their immediate awareness. This might result in moving the pre-service teachers outside their own comfort zone, thereby encouraging them to experience a first read of a book that could be used with their future students. Providing choice can be important; open choice can sometimes be overwhelming for students in any grade. Knowing where to start in sorting through books is a challenge. Therefore, providing a collection as a starting point seemed appropriate to address this issue. 
Attention was paid to the physical presence of books in the room rather than giving pre-service teachers a print book list. Determined to put books in their hands, the teacher educator laid texts out on tables in the classroom and over the course of 15 minutes, pre-service teachers circulated and selected a text to read independently or with a peer. They were encouraged to walk around, pick up a book, flip through it, read a bit, and then jot down two or three titles of interest to them. It was essential to provide class time for this step and in the case of large classes of 40, additional time could accommodate all course participants as they circulated and selected their books.

Once book titles were recorded, a whole class oral session of allocating books occurred. Varied books were chosen from the collection; this was a positive outcome as there were no duplications. Pre-service teachers were assigned reading of the book. The course professor encouraged them to experience the text first as a reader, then secondly, to consider why and how it might be studied in class with students in a target grade English class. As the course focused on teaching methods for grades 7 - 12 English classes, depending on the text, decisions were made about which grade was a best fit. Professor guidance could be acquired on an individual basis, as required. Preservice teachers were invited to sign up for a book talk presentation date over the next eight months.

Book Talks were the second teaching strategy implemented in the course. Guidance was provided in the preparation of book talks. Presenting on their book to peers was valued as it exposed all course participants to a variety of titles. They became the experts on a particular book, and it would be quite possible that others in the course had not read that book. They were reminded that they were speaking to others who had not read the book, and that they didn't want to give away too much of the plot. As prior experience with book talks for some students might have been to create interest or simply encourage others to read the book, they were advised that this aspect was only one component of the assignment. Pre-service teachers were also responsible for acquiring knowledge of the Ontario (Canada) curriculum expectations for a particular grade. Once their target grade was determined, they were exposed to the English Language Arts guidelines to familiarize themselves with the expectations. During their 10 minute oral book talk, they shared a short synopsis of the book they read, why it could be used in their target grade and how it could be studied in a Language/English classroom. Audio Visual aids such as laptop, data projector, and Powerpoint presentations were optional. Assessment criteria for the book talk included suitability of book for target grade, and classroom implementation activities as related to the curriculum expectations.

A third teaching strategy was Senior English Novel reading. The course professor's emphasis was on selecting novels frequently studied in the upper years of secondary school English; many preservice teachers in her past courses were significantly challenged by having limited knowledge of texts for senior classroom study. Preservice teachers had shared this concern with her in past years, and she had observed this herself when evaluating them in school classrooms. When placed on practicum with upper grade English students, this caused a great deal of discomfort and frustration. The content of higher level novels was more difficult as well, therefore, time devoted to addressing this need would be useful during the pre-service course. Although guided selection was in common with strategy one previously discussed, the focus was more limited as only seven book titles were provided for choosing; there were six copies of each one. Therefore, groups of course participants read the same book. It is important to note that not everyone in the course was reading a common text. Whole class study of a book would often be the prior experience of many course participants. Therefore, participating in small groups, within a single classroom, and studying a variety of books was often a new experience for them.

The course professor provided a brief verbal presentation on each book, highlighting the issues and ideas of focus. Copies of the novels were circulated around the room. Pre-service teachers signed up for a selected title on a list. Unlike book selection strategy one, they were assigned partial reading of the first 100 pages of the text, rather than a complete text. This was done in five segments of 20 pages, over the course of five classes. Instructions were given for the out of class reading of 20 pages, then the pre-service teacher would stop, and write a reader response journal entry of a page. The process was repeated five times over consecutive weeks. This strategy was integrated with the next strategy.

The Reader Response Journal was the fourth strategy used in the course. As explained in the section on novel reading, the reader response journal entry was written as the course participants read a portion of the novel. Focusing on their experience with the text, rather than content details, the reader/writer recorded thoughts, feelings, and ideas encountered. "Moving beyond the text itself" was encouraged. Entries were written week by week, rather than in one sitting as they served as preparation for the Book Groups strategy. Reader 
response journals were assessed by the course professor after all five entries had been recorded. Assessment criteria included level of reflection, and engagement with the text.

The fifth and final strategy was Book Groups. It was integrated with both novel reading and response journal writing, the strategies explained above. Over five consecutive weekly classes, the readers of a common novel would meet for 20 minutes to share their reader response entries. Groups of five or six participants were invited to engage in oral discussion. This process did not require creation of a common list of ideas, or consensus on the various issues. It provided opportunities for course participants to share all ideas they chose. They were expected to have both read, and written about the assigned 20 page segment in preparation for active book group involvement. After five weeks of these sessions were completed, all groups gathered together as a whole class, and orally shared the issues and ideas they had discussed in their small groups. This process allowed pre-service teachers to become aware of some issues and ideas in the six novels beyond their own. Informal assessment occurred as the course professor sat in on the book groups over the five weeks.

\subsection{Observations}

Over the past three years, the teacher educator has recorded observations about the effectiveness of the five strategies in her English methods course. She considered what worked well, and what was in need of revision. Although each strategy differed, the common element was that it was chosen to assist pre-service teachers with enhancing their subject matter knowledge for the teaching of English. Observations from some of her reflective notes appear below. As the notes are in personal form, the use of "I" remains, and they are presented below in the voice of the teacher educator. Most of the observations were recorded immediately following a class where the strategy was used with pre-service teachers. At times, jot notes were recorded in her lesson plan binder.

Selected book strategy: In the second week of the course, I set the books out on tables before the class began. Students were receptive to my invite to select a book or two. They immediately left their desks and walked around the room, from table to table, picking up many different books. They seemed to read a bit of the summary on the back, or a page or two inside the cover. They spoke to peers close by at times. I could hear them speaking to each other, sometimes about a particular title or even a topic of interest. They were certainly seeing a number of books over the first five minutes, and I wondered how many of the titles they were familiar with or whether they had read any of them. Assuming the role of a guide on the side, I stayed on the perimeter of the room, as I did not want to influence their decisions. A few times, they approached me and asked for my view about the book. In most cases, I said they should make a personal decision rather than relying on me. I wondered if they were seeking my approval or simply not confident in choosing a new book right away. In fact, there were a few books I had not yet read myself; I had included them in the collection under the recommendation of former students in the course. This has been my practice in the past few years.

I observed that some of them had a book or two in mind, and rather than writing down the title, they took it to their desk. I encouraged them to leave books for all to see initially. I suspect my directions were not entirely clear and that was the reason for them physically selecting the book. After about 15 minutes, most seemed to have at title or two in mind, and a few were still wandering around. I decided to call time and then brought the class together. I asked who had a book in mind, and orally they shared. A few duplicates were suggested, and in some cases, two students paired themselves and decided to work on the book together. I asked them about the process of selection. In two of the classes that week, two mentioned that they enjoyed seeing the books rather than choosing from a list. One said that a list would be faster; although this was true, it did take class time to give them enough selection time, then additional time to sort through the possible titles out loud as a class. That part of the process was informative for me as it gave me a better sense of which books caught their interest

Book talks: Once the book selection strategy was completed, I shared the expectations for the book talk assignment. I used a powerpoint presentation display on the data projector through my computer to highlight parameters. I modeled using a novel from the collection that had not been selected by students. Preparation for the 10 minute talk to their peers had a few steps. Firstly, they were advised to read the entire book first. If they were working with a partner, they both would take turns with the reading. I encouraged them to jot down their ideas and reactions to the book. If they were paired, they could discuss them with their partner. Based on their notes, they were then responsible for selecting a target grade for study of the text. Time would need to be taken to search through the curriculum expectations document for English Language. Four classes later, book talks (presentations) began. All work in preparation for book talks was completed outside of class time. 
This strategy was integrated with the other course activities on the weekly course schedule. Since book talks would occur over six months, there was no intent to block more than two in a single class.

On the first day of book talks, student presenters effectively shared their book, providing a brief synopsis, stating issues in the text, and curriculum links to a specific grade. At times, the synopsis took up a great deal of the allotted time. Over the first few weeks of presentations, students seemed to become more at ease with spending less time on plot details, and focusing more on how the book might be used with students in classrooms. Teaching and learning strategies were shared for study of the specific book. I was impressed with the range of ideas and insights they mentioned as related to their books. Participants in the course, beyond the presenters, had opportunities to acquire an awareness of many books over the weeks of book talks. This was a positive as it could only contribute to their knowledge base for English teaching. Although they would not be reading all of these books during the course, it certainly provided possibilities for future study. Many of the book talk presenters conveyed enthusiasm for the content of their chosen book, and reasons for why it was worthy of classroom study with English Language Arts students. The challenge for many presenters was the time limit of 10 minutes. If they spend too much time on plot synopsis, they ran short of time for classroom implementation, and suitability for selected grade. These three components formed the assessment criteria, therefore, all needed to be addressed.

Most presenters did a particularly effective job of explaining how the book could be studied with students. I noted that some struggled with articulating why the book should be studied. Although I recognized that they knew it could be studied, as it was part of the collection shared by me, as their professor, I still wanted them to go deeper at times. I found that as the weeks of book talks moved forward, they began to display a greater sense of why a text could be selected for classroom learning. I suspect that after some time out on placements, they had gained more experience with books in classrooms. In a few of the classes, a student offered to compile a list of titles and authors as a resource which they shared within their class. In cases where powerpoint presentations were used for book talks, students had the opportunity to include those visuals, too. After copying these resources onto a USB key, it was circulated to others who wished to copy it onto their laptop computers.

Opportunities for peer teaching was a strength of this strategy. Oftentimes a teacher or professor can spend a block of time sharing text titles with students. Although this is an informative approach, there are other ways of conveying this information. I've noticed that sometimes students might listen more carefully to a peer, especially in a teacher education program where they are all immersed of the process of becoming teachers. They share a common goal and as future teachers of Language or English, there may be a desire to guide one another. I observed that both presenters and listeners seemed to enjoy these talks. A few who worked with a partner mentioned to me that they benefitted from talking to their partner about the book, as they prepared for their talk. Maybe it served as a mini-book club, where talking about a book can result in greater understanding. I wonder whether in future, the book talk could become a paired assignment, rather than an individual one. For now, I'll leave the choice up to student preference. I continue to learn a great deal about how books in the collection could be studied with secondary English students. I am always pleasantly surprised at how a book can be approached in various ways, depending on the interest, grade level and aspects found within the book by a reader. Students' own reading and thinking about a book for their book talk assignment allowed them to take time with a text. The preparation steps for the book talk were important, and perhaps maybe even more valuable than the presentation itself.

Senior English novel reading: Students were actively engaged in reading their selected book group novels. Only two or three visited my office the day after their book choice, and asked to switch novels. I was interested that they had started their reading right away, and quickly decided that their attention wasn't caught with that particular book. They had no difficultly selecting another of the six novels and proceeding to reading the assigned portion before our next week's class. Limiting the choice to seven novels helped facilitate book groups. I wonder about adding some other novels for the Senior English collection for the course. I spoke to a local secondary English department head last year and he offered some current suggestions from his classroom practice. Due to increased class size in my courses, sometimes there are 45 students; therefore, the number of novels could be increased. The challenge is if more book titles are offered, it may result in some groups of three students rather than five or six which I think can be more conducive to extended discussion. I'll rethink this idea next year before purchasing more books. University budgets continue to be restricted and books are expensive. I always strive to get books into the hands of students, although there are challenges in doing so in times of fiscal restraint.

Reading a book, outside of class time, in weekly segments of 20 pages was manageable for 
course participants. As students of English prior to enrolling in the teacher education program, most were well practiced in required novel reading. This strategy was different though as they were asked to stop reading at specific intervals. They had limited experience with reading a section of a novel, as they had been assigned reading of entire books in their previous university courses! This was an interesting observation to me. I thought they might have a preference for reading less due to their heavy course workload in the Education program. I initially was surprised and then realized that when one is reading fiction, you get involved in the story and stopping can be an interruption. In some cases, a few said they were frustrated. This seemed to be alleviated over the first week or two as they gained an appreciation for the power of reading and writing together. The response journal strategy was incorporated at the same time, and by asking them to stop reading at specific intervals, the approach allowed time for writing.

Reader response journals: As students read sections of their novel, they wrote their responses. Most kept up to date with the reading and writing. They knew they had to be prepared for the next class, and while one week passed between the weekly course sessions, I observed they were on track. Some chose to write their entries by hand, while others word processed on their computers. Whichever method those chose, they were asked to bring a print copy to class to facilitate discussion with peers in their book group. After the first entry was prepared, a few asked me to look and see if they were on track.

Although I had stated expectations for the assignment, I realized that some were not comfortable with responding to literature in first person. As graduates of programs in English, they were used to formal writing rather than informal writing. After a few queries, we had a whole class discussion about the expectation that they were to write in their own voice, and share their personal encounter with the book. Their focus was to be placed on personal reading, rather than how this book could be studied in an English secondary classroom. I shared some research on response to literature and Louise Rosenblatt's transactional theory. They were receptive to a theoretical basis for the strategies I had selected for the course. Responding to the text, rather than analyzing was emphasized for their journal assignment. The immediate response in writing after reading was also stressed. We discussed that a response can move into an analysis, therefore they aren't completely separate types of writing. I reminded myself that we should spend some time on the theory of response to literature; it was on the agenda for a future class. It is interesting to consider where in fact is the best place for this course component. If the focus is on too much theory early on, students can sometimes struggle with it. Once some practical aspects of English teaching are addressed, the theory can sometimes be more meaningful to them. Based on the questions the students asked in this class, I heard them inquiring further about why they had to do the reading of the novel and writing in their journal together. If I had spent some time on the theory of reader response first, it might have been a smoother transition for them. The theory does indicate that one's understanding of literature can be deepened if you write in a reflective way, as you read. That makes it an excellent fit for this course, especially as the intent is to help enhance students' subject matter knowledge in English. When I introduce this strategy with a future class, I will make that change. I collected the reader response journals for assessment at the end of the fifth session of book groups.

Book groups: The book group strategy was integrated with novel reading, and reader response journals. It focused on the oral aspect, and giving students time for talking about books. Dialoging about books was effective and I noted in each class that the students often got started and didn't want to stop talking! I observed very little off task behavior during these 30 minute blocks. In some classes, I actually extended the book group time as they were so actively engaged, I didn't want to interrupt the process. I noticed that they used their journal entries as a reference point, although they did not rely solely on them. They took turns in speaking, rather like in a conversation rather than each student speaking on by one according to their seating arrangement. This was an interesting feature as each group did function somewhat differently from each other. I had intentionally not stated how the group should conduct themselves. I felt that as education students, they could feel their way through this process in the early stages.

After the first class of book groups, I started sitting in on the groups to get a clearer sense of the discussion. Initially, it was a challenge because in one group, they stopped talking when I sat down. The group members all looked at me, and I just said, "go ahead...", and they proceeded. A few were tempted to ask me a question about the book, and I would then ask them to check with a peer. It was odd for a little bit of time, as I suspect they were just trying to involve me as I was sitting in on their group. When I stood to one side of the classroom, it was difficult to grasp the talk from seven groups, therefore I tried to lean in and eavesdrop a little. The noise level increased as the conversations continued; it was a particular pleasure to hear so many of them talking about 
literature. By sitting in on each group, I was much more able to listen to the dialogue, but I wonder whether my presence did change the flow of conversation. We did talk about this issue as a class once the five book group sessions had ended. Some of the students shared with me that my presence was a distraction as they felt like they were being evaluated. I had already advised them that there was no mark assigned to book groups, only the reader response journal. Often pre-service teachers assume they are constantly being evaluated, even if it is informally. I believe that talking about their novels helped them consider others views about the common text they had read. It wasn't a consensus seeking activity; what was important was that they had read, then written on their own, before sharing their thoughts with others. In my experience, I believe by becoming aware of ideas in a book, there is a greater likelihood it could be selected for classroom use.

\section{Discussion}

As the teacher educator's observational notes revealed, all five strategies were incorporated into the English methods course. The pre-service teachers immersed themselves in using the strategies over the weekly course sessions. They weren't simply learning by hearing about them, they were modeling the strategies as participants. At the beginning, a few questioned the process and wondered how they could act like secondary school students in the act of trying each strategy. It was a thoughtful query and worthy of further consideration. The teacher educator invited pre-service teachers to practice the strategy itself, as readers, rather than as novice teachers thinking of how their own students might perform a particular strategy. Research in teacher development [14] supports the need for teachers "to experience a pedagogical approach from the standpoint of learner before they are able to implement this approach in their own classrooms" (p. 20). Perhaps the teacher educator could consider devoting additional time to oral debriefings following completion of each strategy used in the course. How a pre-service teacher approaches a strategy is somewhat different than that of one's own students in a secondary classroom, although there may be some similarities.

This leads to the question of whether personal experiences with using strategies actually have an impact on whether novice teachers might try these five strategies in their own English classrooms upon completion of the teacher education program. Previous research may shed some light on this inquiry. McIntosh [15] (the teacher educator in this study) has explored a novice teacher's implementation process for reader response journals. The study participant revealed "although she didn't introduce response journals with a strategy she learned in her preservice program, she clearly indicates that the desire to use journals in her own classroom originated there" (p. 170). Further exploration of this issue goes beyond the parameters of this study.

\section{Conclusion}

Through integration of revised teaching strategies, the teacher educator has observed some enhancement of pre-service teachers' subject knowledge. Preliminary findings, in the form of personal observations, revealed the impact of her intervention. As the research results have shown, they offer positive possibilities for further exploration. Selecting books under guided teacher educator assistance served as a stimulus for course participants to actively engage in reading, writing and speaking. Through effectively interweaving these English Language Arts strands in the five strategies and granting them a prominent place in the Methods' weekly classes, pre-service teachers had continuous opportunities to build their subject matter knowledge. Sometimes this intent was obvious to the course participants, and at other times, it was a seamless occurrence. Aspects of the content, the literature itself, were explored in informal ways; suggested opportunities for how such strategies might be used in classrooms were shared.

After the first six weeks of the one year English methods course, it came obvious to the course professor that her pre-service teachers were increasing their confidence in text awareness. Although it may be difficult to accurately measure this finding, it is a significant point. As pre-service teachers prepare for their own future students, they will have opportunities beyond the teacher education program to select texts for their own students. Building subject matter knowledge is an ongoing process and an integral part of a teacher's professional development.

The teacher educator continues to engage in rethinking her practice in light of acquiring a greater awareness of pre-service teachers' experiences in using the text exploration strategies in this study. Positive outcomes were observed in implementing the five strategies within her course, and for that reason, she will continue to work at enhancing her own role as one who guides novice teachers. There are many challenges ahead for these pre-service teachers who are striving to meet the needs of their own students, and the profession's expectations for the field of English teaching in secondary classrooms. 


\section{References}

[1] J. Mayer, "English teacher education as literacy teacher education", English Education, National Council of Teachers of English, Urbana, IL., 2012, pp. 180-187.

[2] Langer, J., Envisioning Knowledge: Building Literacy in the Academic Disciplines, Teachers College Press, New York, 2011.

[3] Kosnik, C., and C. Beck, Priorities in Teacher Education: The 7 Key Elements of Pre-service Preparation, Routledge, London, 2009.

[4] P. Grossman, and A.Schoenfeld, "Teaching subject matter", in L. Darling Hammond and J. Bransford (Eds.), Preparing Teachers for a Changing World: What Teachers Should Learn and Be Able to Do, Jossey-Bass, San Francisco, 2005, pp. 201-227.

[5] L. S. Shulman, "Knowledge and teaching: Foundations of the new reform", Harvard Educational Review, Harvard Education Publishing Group, 1987, pp. 1-22.

[6] Kosnik, C., J. Rowsell, P. Williamson, R. Simon, and C. Beck (Eds.), Literacy Teacher Educators: Preparing Teachers for a Changing World, Sense Publishers, Rotterdam, 2013.

[7] S. Feiman-Nemser, "From preparation to practice: Designing a continuum to strengthen and sustain teaching", Teachers College Record, Columbia University, 2001, pp. 1013-1055.

[8] Beach, R., D. Appleman, S. Hynds, and J. Wilhelm, Teaching Literature to Adolescents, Routledge, New York, 2010.

[9] National Council of Teachers of English, Guidelines for the preparation of teachers of English Language Arts, NCTE, Urbana, Ill., 2006.

[10] N. Watkins and J. Ostenson, "Navigating the text selection gauntlet: Exploring factors that influence teachers' choices", English Education, National Council of Teachers of English, 2015, pp. 245-275.

[11] Ministry of Education, The Ontario Curriculum Grades 11 and 12 English, Queen's Printer for Ontario, Toronto, 2007.

[12] McIntosh, J., S. Schleppe, and A. White, Modern Morsels: Selections of Canadian Poetry and Short Fiction, McGraw-Hill Ryerson, Toronto, 2012.

[13] McGraw-Hill Ryerson, Canlit Digital Collection, Toronto, 2011, Retrieved from http://www.iLit.ca (Access Date: 13 October, 2014).

[14] P. Grossman, P. Smagorinsky, and S. Valencia, "Appropriating tools for teaching English: A theoretical framework for research on learning to teach", American
Journal of Education, The University of Chicago Press, 1999, pp. 1-29.

[15] J.E. McIntosh, "Reader response journals in intermediate Language Arts: Reflection on the implementation process", English Quarterly, Canadian Council for Teachers of English Language Arts, 2008, pp. 16-21. 